\title{
OPPORTUNISTIC AND OTHER INTESTINAL PARASITIC INFECTIONS IN AIDS PATIENTS, HIV SEROPOSITIVE HEALTHY CARRIERS AND HIV SERONEGATIVE INDIVIDUALS IN SOUTHWEST ETHIOPIA
}

\author{
Zelalem T. Mariam ${ }^{1}$, Gemeda Abebe $^{2}$ and Andargachew Mulu ${ }^{3 *}$
}

Abstract

Background: Human Immunodeficiency Virus (HIV) infection leads to acquired immunodeficiency syndrome (AIDS) and major causes of morbidity and mortality of such patients are opportunistic infections caused by viral, bacterial, fungal and parasitic pathogens.

Objectives: To determine the magnitude of opportunistic and non-opportunistic intestinal parasitic infections among AIDS patients and HIV positive carrier individuals

Method: Cross-sectional study was conducted among AIDS patients, HIV positive healthy carriers and HIV negative individuals in Jimma University Hospital, Mother Theresa Missionary Charity Centre, Medan Acts Projects and Mekdim HIV positive persons and AIDS orphans' national association from January to May, 2004. Convenient sampling technique was employed to identify the study subjects and hence a total of 160 subjects were included. A pre-tested structured questionnaire was used to collect socio-demographic data of the patients. Stool samples were examined by direct saline, iodine wet mount, formol-ether sedimentation concentration, oocyst concentration and modified Ziehl-Neelsen staining technique.

Results: Out of 160 persons enrolled in this study 100(62.5\%) (i.e. 65 male and 35 female) were infected with one or more intestinal parasites. The highest rate $36(69.2 \%)$ of intestinal parasites were observed among HIV/AIDS patients, followed by HIV positive healthy carriers $35(61.4 \%)$ of and HIV negative individuals (29(56.9\%). Isospora belli 2(3.9\%), Cryptosporidum parvum 8(15.4\%), Strongyloides stercoralis 6(11.5\%) and Blastocystis $2(3.9 \%)$ were found only in HIV/AIDS groups

Conclusion: I. belli, C. parvum, S. stercoralis and Blastocystis are the major opportunistic intestinal parasites observed in HIV/AIDS patients. Therefore, early detection and treatment of these parasites are important to improve the quality of life of HIV/AIDS patients with diarrhoea.

Key words: HIV/AIDS patients, HIV positive healthy carriers, HIV negative individuals

\section{Introduction}

According to recent WHO report more than 39 million people worldwide are infected with HIV, the majority of whom, approximately 25.4 million people, live in sub-Saharan Africa. Ethiopia has been facing an epidemic of HIV-1 subtype C, with low frequency of subtypes A and D. As of the end of 2004, 1.5 million people are living with the virus with an estimated HIV prevalence of $4.4 \%$ (1). Similarly, intestinal parasitic infections are widely distributed throughout the world, especially in tropical and sub tropical areas of the developing countries. It is estimated to cause one million deaths a year (2). Like other developing countries, in Ethiopia infections with the major human gastrointestinal nematodes are rampant and the prevalence of infections with gastrointestinal nematodes is variable from place to place and can be as high as $90 \%$ (3-6).

HIV/AIDS compromises the immunity of the body. This predisposes to various opportunistic infections of viral, bacterial, fungal and parasitic origins. Among those parasitic opportunistic infections, Cryptosporidum parvum, Isospora belli, Cyclospora cayetanensis and Microspordia are the most frequent causes of diarrhoea. A study conducted

Correspondence to: Andargachew Mulu, University of Gondar, College of Medicine and Health Sciences, School of Medicine, Department of Microbiology and Parasitology, P. O. Box 196, Gondar, Ethiopia E-mail: andargachewmulu@yahoo.com, Tele: +251911721167

${ }^{1}$ Haromaya University, College of Health Sciences, Department of Medical Laboratory Technology P. O. Box 547, Harer, ${ }^{2}$ Jimma University, Faculty of Medical Sciences, School of Medical Laboratory Technology, P. O. Box 378, Jimma , ${ }^{3}$ University of Gondar, College of Medicine and Health Sciences, Schoo of Medicine, Department of Microbiology and Parasitology, P. O. Box 196, Gondar in Brazil showed higher rate of intestinal parasitic infection in AIDS patient than HIV positive and HIV negative subjects with a prevalence of $2.8 \%$ I. belli among AIDS patient (7). Similarly, 5\% prevalence of $I$. belli was reported from Thailand among HIV positive individuals at different immunity status (8). Another studies conducted in Haiti also showed a marked rate of $I$. belli $(15 \%)$, Elsavador (7.4\%), Mexico (5.4\%), Cuba $(1.5 \%)$, and India (16.6\%) (9-12). A study carried in Tanzania showed high prevalence of intestinal parasitosis with $25.9 \%$ prevalence of I. belli among HIV positive. Similarly, high rate of this parasites were reported in different African in Senegal (15.3\%), Ivory Coast $(17.9 \%)$ and Zaire (19\%) (13-16). In general, variation in the prevalence of opportunistic parasitic intestinal infections (like I. belli, C. parvum) and non opportunistic parasitic infections (like Ascaris lumbricoides, Garadia lamblia) was observed at different immunity status of HIV infection in different countries.

In Ethiopian, previous studies showed high prevalence of intestinal parasites like A. lumbricoides, E. histolytica, G. lamblia, T. saginata in HIV positive individuals than HIV negative and the difference increase with increasing the level of immunodeficiency (17-18). However, information regarding the magnitude of opportunistic parasitic infections among HIV/AIDS patients, HIV positive healthy carriers and HIV negative healthy individuals are scarce and not well studied. The purpose of this study was, therefore, to determine the magnitude of opportunistic and other intestinal parasitic infections among AIDS patients, HIV positive healthy carriers and HIV negative individuals in Southwest Ethiopia. 


\section{Methods and materials}

\section{Study design, area and period:}

This cross sectional study was conducted Jimma University Hospital, Mother Theresa Missionary Charity Centre, Medan Acts Project and Mekdim HIV Positive Person and AIDS orphans National Association from February to March 2004.

Jimma town is the capital city of Jimma administrative zone, located 335 kilometres south west of Addis Ababa. Jimma Hospital is a referral and teaching Hospital. Mother Theresa Missionary Charity Centre is a place where helpless; care seeking patients admitted and receives medical services. It also support HIV/AIDS suspected and laboratory confirmed patients by giving medical and other services. Jimma Medan Acts Project is under Kale Heywet Church and provides various services like prevention, counselling, social support and training on HIV/AIDS. Mekdim HIV Positive Persons and AIDS Orphans National Association have four major programs like house to house care, counselling, social support, HIV/AIDS education service.

\section{Study subjects}

The study subjects were those HIV/ AIDS, HIV positive healthy carriers and HIV negative individuals from the above mentioned organizations.

\section{Sampling Technique}

A convenience sampling technique was used to determine the magnitude of opportunistic and other intestinal parasite in among HIV/AIDS HIV positive healthy carriers and HIV negative individuals attending each organization.

\section{Socio-demographic data}

A pre-designed structured questionnaire was utilized to collect socio-demographic characteristics of the patients.

\section{HIV serology}

The presence of HIV-1 antibodies in the serum will be determined using rapid HIV-1 diagnostic test kits following the manufacturers' instructions. The results will be then interpreted following the current national algorithm for screening of sera for HIV-1 infection that was adopted from WHO. In brief, the sera will be first tested with Determine HIV-1/2. If the result is found to be positive it will be taken as positive. If not, it will further be tested with Capillus HIV-1/2. If the result of Capillus was found negative, then the serum was considered as negative for HIV-1 antibodies, if not it will be tested for a third time with a tiebreaker, Unigold HIV$1 / 2$ and / or the presence of HIV antibodies in serum will be determined by the by an enzyme linked immunosorbent assay following the manufacturer's instruction (19).

\section{Stool examination}

Subjects were provided a labelled leak proof container, toilet paper, applicator stick and informed to put about 1-2 gm stool using applicator stick. Then stool specimens were examined by direct saline, iodine wet mount preparation and formol ether sedimentation methods following the standard procedure. Oocyst concentration and modified Ziehl Neelsen ( $\mathrm{Zn}$ ) staining techniques were used for the detection of oocyst of Cryptosporidium pavum and Isospora belli following the standard procedure (20). Two smears were prepared from each sample and one examined by experienced senior medical laboratory technician and the other by the principal investigator independently.

\section{Data analysis and interpretation}

The data was computerized in Excel 97 software and analyzed by EPI info 6 statistical soft ware packages.

\section{Ethical approval:}

This study was conducted after ethical clearance from the institutions Jimma University and after informed consent is obtained from the study subjects. Treatment of HIV/AIDS and intestinal parasitosis were made following the existing clinical practice.

\section{Results}

\section{Description of the study subjects}

A total 160 subjects from Jimma Hospital, Mother Theresa Missionary Charity Centre, Medan Acts Projects, Mekdim HIV Positive Persons and AIDS Orphans National Association were enrolled in the study. They were categorized into three groups by their clinical and HIV laboratory test results following the national guidelines. Based on this 52(32.5\%), 57 (35.6\%) and $51(31.9 \%)$ were HIV/AIDS, HIV positive health carrier and HIV negative individuals, respectively. The demographic data of the study subjects is summarized in table one and table 1 and 2 .

The mean age of the subjects were 29, 30 and 25 years for HIV /AIDS patients, HIV positive healthy carriers and for HIV negative individuals with a range of 15-55, 18-75 and 16-42 years for HIV/AIDS patients, HIV positive healthy carriers and for HIV negative individuals, respectively. The majority of the subjects $103(64.4 \%)$ were male and the remaining $57(35.6 \%)$ were females making the male to female ration of $1.8: 1$. The majority of infected individuals were found in the age group 25-34 years of HIV/AIDS (34.6\%) \& HIV positive healthy carriers $(28.1 \%)$ but $15-24$ of HIV negative individuals $(31.4 \%)$. Thirty two $(61.5 \%)$ of HIV/AIDS patients, $27(47.3 \%)$ of HIV positive healthy carriers and $16(31.4 \%)$ of HIV negative individuals were unemployed. And the majority of the subjects were found to be literate. Equal number of single and married individuals (i.e. 19(36.5\%) were found among HIV/AIDS patients, and $26(45.6 \%)$ of HIV positive healthy carriers were found to be married and 33(64.7\%) of HIV negative 
individuals were single. The majority, 33(63.4\%) of HIV/AIDS and 39 (76.5\%) of HIV negative individuals were Orthodox Christian in religion, but equal number of Orthodox and Muslim individuals were found among HIV positive healthy carriers (i.e. 22(38.6\%).

Table 1: The sociodemographic characteristics of HIV/AIDS, HIV positive healthy carriers and HIV negative individuals

\begin{tabular}{|c|c|c|c|}
\hline \multirow[t]{2}{*}{ Characteristics } & \multicolumn{3}{|c|}{ Clinical status of study subjects } \\
\hline & $\begin{array}{l}\text { HIV/AIDS } \\
\text { Patients } \\
\text { No (\%) }\end{array}$ & $\begin{array}{l}\text { HIV positive } \\
\text { Healthy } \\
\text { carrier } \\
\quad \text { No (\%) }\end{array}$ & $\begin{array}{l}\text { HIV } \\
\text { negative } \\
\text { individuals } \\
\text { No (\%) }\end{array}$ \\
\hline \multicolumn{4}{|l|}{ Marital status } \\
\hline Single & $19(36.5)$ & 18(31.6) & $33(64.7)$ \\
\hline Married & $19(36.5)$ & $26(45.6)$ & $12(23.5)$ \\
\hline Divorced & $13(25)$ & $10(17.5)$ & $4(7.8)$ \\
\hline Widowed & $1(2)$ & $3(5.30$ & 2(4) \\
\hline \multicolumn{4}{|l|}{ Educational status } \\
\hline Illiterate & $12(23.1$ & $12(21.1)$ & $5(9.8)$ \\
\hline Literate & $40(76.9$ & $45(78.9)$ & $46(90.2)$ \\
\hline \multicolumn{4}{|l|}{ Religion } \\
\hline Orthodox & $33(63.4)$ & $22(38.6)$ & $40(78.4)$ \\
\hline Protestant & $2(3.8)$ & $13(22.8)$ & - \\
\hline Muslim & $16(30.8)$ & $22(38.6)$ & $11(21.6)$ \\
\hline Catholic & $1(2)$ & - & - \\
\hline \multicolumn{4}{|l|}{ Occupations } \\
\hline Employed & $5(9.6)$ & $5(8.8)$ & $8(15.6)$ \\
\hline Not employed & $31(60)$ & $25(43.8)$ & $16(31.4)$ \\
\hline Students & $2(3.8)$ & $8(14)$ & $14(27.5)$ \\
\hline House wife & $3(5.8)$ & $5(8.8)$ & $2(3.9)$ \\
\hline Farmers & $5(9.6)$ & $3(5.3)$ & $10(19.6)$ \\
\hline Others & $6(11.5)$ & 11(19.2) & $1(1.8)$ \\
\hline Total & $52(100)$ & $57(100)$ & $51(100$ \\
\hline
\end{tabular}

Table 2: Age and sex distribution of HIV/AIDS patients, HIV positive healthy carriers and HIV negative individuals

\begin{tabular}{|c|c|c|c|c|c|}
\hline \multirow[b]{2}{*}{$\begin{array}{l}\text { Age } \\
\text { (years) }\end{array}$} & \multirow[b]{2}{*}{ Sex } & \multicolumn{3}{|c|}{ Clinical status of study subjects } & \multirow{2}{*}{$\begin{array}{l}\text { Total } \\
\text { No (\%) }\end{array}$} \\
\hline & & $\begin{array}{l}\text { HIV/AIDS } \\
\text { patients } \\
\text { No (\%) }\end{array}$ & $\begin{array}{l}\text { HIV positive } \\
\text { healthy } \\
\text { carriers } \\
\text { No (\%) }\end{array}$ & $\begin{array}{l}\text { HIV negative } \\
\text { individuals } \\
\text { No (\%) }\end{array}$ & \\
\hline \multirow[t]{2}{*}{$15-24$} & Male & $4(7.7)$ & $7(12.3)$ & $13(25.5)$ & $24(15)$ \\
\hline & Female & $7(13.5)$ & 8(14) & $14(27.5)$ & 29(18.1) \\
\hline \multirow[t]{2}{*}{$25-34$} & Male & 22(42.3) & 15(26.3) & 17(33.3) & $54(33.8)$ \\
\hline & Female & $5(9.6)$ & 12(21.1) & $4(7.8)$ & 21(13.1) \\
\hline \multirow[t]{2}{*}{$35-44$} & Male & $11(21.2)$ & $7(12.3)$ & $3(5.9)$ & 21(13.1) \\
\hline & Female & $2(3.9)$ & $2(3.5)$ & $\mathbf{0}$ & $4(2.5)$ \\
\hline \multirow[t]{2}{*}{$\geq 45$} & Male & $1(1.9)$ & $3(5.3)$ & 0 & $4(2.5)$ \\
\hline & Female & $\mathbf{0}$ & $3(5.3)$ & $\mathbf{0}$ & $3(1.9)$ \\
\hline Total & & $52(100)$ & $57(100)$ & $51(100$ & $160(100)$ \\
\hline
\end{tabular}

\section{Opportunistic intestinal parasites infection:}

Out of 160 persons examined $100(62.5 \%)$ (i.e. 65 male and 35 females) were infected with one or more intestinal parasites. Among these 36(69.2\%) of HIV/AID patients, 35(61.4\%) of HIV positive healthy carriers and $29(56.9 \%)$ of HIV negative persons were infected with one or more intestinal parasites making the overall prevalence of intestinal parasitosis $62.5 \%$. The highest prevalence of intestinal parasitosis in general was higher among HIV/AIDS patients than the carrier and apparently health individuals.

Opportunistic intestinal parasites: Isospora belli, Cryptosporidum species, and Blastocystis species were highly prevalent in HIV/AIDS groups with magnitude of $2(3.9 \%), 8(15.4 \%)$, and $2(3.9 \%)$, respectively. These parasites were not identified among HIV positive healthy carriers and HIV negative individuals.

\section{Non opportunistic intestinal parasites:}

As indicated in table 3, the most frequent intestinal parasites diagnosed were Enatameoba histolytica, Ascaris lumbricoides, Trichuris trichiura, Giaradia lamblia, Strongyloides stercoralis, hookworm, Hymenolopies nana and Enteriobious vermicularis with prevalence of $38 \%(38 / 100), 37 \%$ (37/100), 21\% (21/100), 7(7/100), $7 \%(7 / 100), 3 \%(3 / 100)$ and $1 \%(1 / 100)$, respectively. Sixty three percent of the patients had single infection. Multiple infection i.e. infection with 2, 3 and 4 different species of intestinal parasites were observed in $33(33 / 100), 4 \%$ $(4 / 100)$ and $1 \%(1 / 100)$ patients, respectively (Table 4$)$. 
Table 3: Distribution of intestinal parasites identified among HIV/AIDS, HIV positive healthy carriers and HIV negative individuals

\begin{tabular}{llll}
\hline & \multicolumn{3}{c}{ Clinical status of study subjects } \\
\cline { 2 - 4 } $\begin{array}{l}\text { Intestinal parasites } \\
\text { (number of parasites) }\end{array}$ & $\begin{array}{c}\text { HIV/AIDS } \\
\text { patients } \\
\text { N (\%) }\end{array}$ & $\begin{array}{l}\text { HIV positive } \\
\text { healthy } \\
\text { carrier } \\
\text { N (\%) }\end{array}$ & $\begin{array}{l}\text { HIV negative } \\
\text { individuals } \\
\text { N (\%) }\end{array}$ \\
\hline Ascaris lumbricoide (37) & $10(19.2)$ & $13(22.8)$ & $14(27.5)$ \\
Entamoeba histolytica (38) & $9(17.3)$ & $12(21.1)$ & $17(33.3)$ \\
Trichuris trichiuria (21) & $7(13.5)$ & $12(21.1)$ & $2(3.9)$ \\
Strongyloides stercoralis (7) & $6(11.5)$ & $1(1.8)$ & 0 \\
Garadia lamblia (17) & $5(9.6)$ & $6(10.6)$ & $6(11.8)$ \\
Hook worm (7) & $5(9.6)$ & $1(1.8)$ & $1(2)$ \\
Hymenolopis nana (3) & $2(3.9)$ & 0 & $1(2)$ \\
Enterobius vermacularis (1) & 0 & $1(1.8)$ & 0 \\
Cryotosporidum species (8) & $8(15.4)$ & 0 & 0 \\
Isospora belli (2) & $2(3.9)$ & 0 & 0 \\
Blastocystis species (2) & $2(3.9)$ & 0 & 0 \\
Total & $36(69.2)$ & $35(61.4)$ & $29(56.9)$ \\
\hline
\end{tabular}

Table 4: Magnitude of single and multiple intestinal parasite infection of HIV/AIDS, HIV positive healthy carriers and HIV negative individuals

\begin{tabular}{llllll}
\hline & \multicolumn{5}{c}{ Number of parasites identified } \\
$\begin{array}{l}\text { Clinical status of } \\
\text { study population }\end{array}$ & & $\begin{array}{l}\text { Two } \\
\text { N(\%) }\end{array}$ & $\begin{array}{l}\text { Three } \\
\text { N (\%) }\end{array}$ & $\begin{array}{l}\text { Four } \\
\text { N(\%) }\end{array}$ & N (\%) \\
\hline $\begin{array}{l}\text { HIV/AIDS } \\
\text { N=36 }\end{array}$ & $24(63.9)$ & $10(27.8)$ & $2(5.6)$ & $1(2.7)$ \\
$\begin{array}{l}\text { HIV positive healthy } \\
\text { carriers N=35 }\end{array}$ & $22(62.9)$ & $12(34.3)$ & $1(2.9)$ & 0 \\
HIV negative & $\mathrm{N}=29$ & $17(58.6)$ & $11(37.9)$ & $1(3.5)$ & 0 \\
Total & & $\mathbf{6 3 ( 6 3 )}$ & $\mathbf{3 3 ( 3 3 )}$ & $\mathbf{4 ( 4 )}$ & $\mathbf{1 ( 1 )}$ \\
\hline
\end{tabular}

\section{Discussion}

As the largest lymphoid organ in the body the gastrointestinal tracts is a potential reservoir for human immunodeficiency virus (HIV), the causative agent of acquired immunodeficiency syndrome (AIDS), and it is important site for HIV induced immunodeficiency. The resulting defects in cellular and humeral defence mechanism predispose the gastrointestinal tract to a spectrum of viral, fungal, bacterial and parasitic pathogens (21).

In this study Isospora belli were found in $2(3.9 \%)$, Cryptosipridum parvum in $8(15.9 \%)$, and Blastocystis in $2(3.9 \%)$ of HIV/AIDS patients. These parasites were not found in other groups of the subjects. The current prevalence of Isospora belli was similar to study carried in Brazil, Cuba $(1.5 \%)$ and France $(2 \%)$ where $2.8 \%$, $1.5 \%$ and $2 \%$ prevalence rate of I. belli among HIV/AIDS patients were reported, respectively $(7,11)$. It was also in agreement with a report from Gondar (22) and from Addis Ababa where a 2.4 and $1.4 \%$ prevalence rate of $I$. belli among HIV/AIDS patients with diarrhoea were reported. However, this $3.9 \%$ prevalence of $I$. belli was lower as compared with a study from Mexico, El
Salvador, Haiti, India, Ivory Coast, Senegal and Zaire in which a high rate $5.5 \%, 7.4 \%, 15 \%, 16.6 \%, 17.9 \%$, $15.3 \%$ and $19 \%$ of I. belli among HIV patients have been reported $(9,12,13,14)$. This might be due to high prevalence of this parasite in those target populations and geographic areas.

The prevalence of Cryptosporidum parvum in the current study $16 \%$ which was similar with a study conducted in Jimma and Addis Ababa where a 17\% (15) and $17 \%$ (23) prevalence of C. parvum were reported, respectively and also in agreement with a report from Brazil (13\%) (15,34). However, it was higher than a report from Ivory Coast $(7.5 \%)$, Zaire $(8 \%)$, Senegal $(13.9 \%)$, Cuba $(11.9 \%)$ and India $(2.1 \%)(11,12,14,15)$ and lower than studies carried in Addis Ababa ( 25.9\%) and France (37.3\%)( 10).

Besides those opportunistic intestinal parasites, the non opportunistic intestinal parasite Strongyloides stercoralis were diagnosed with a prevalence of $7 \%$. This was similar with the study carried in Ivory Coast (13.4\%) (14), but higher than studies carried in Addis Ababa (3.4\%), Jimma (8\%), Brazil (3.9\%) and Tanzania (9.8\%) $(8,13,17,24)$. The other non opportunistic parasite Balstocystis species, which has been reported as causative agents of diarrhoea in a number of cases in patients with AIDS was detected slightly higher than in Addis Ababa (1(0.9\%) among HIV/AIDS with diarrhoea and $1(2.4 \%)$ among HIV positive without diarrhoea). This might be due to similar reasons for higher Strongyloides stercoralis infection (13).

Based on the above finding Isospora belli, Cryptosporidum species, Strongyloides stercoralis and Blastocystis were higher among HIV/AIDS groups, but HIV/AIDS groups do not have more intestinal parasites than HIV positive healthy carriers and HIV negative individuals $(\mathrm{P}>0.1)$. This was similar to the study carried among HIV/AIDS patients in Addis Ababa and Jimma $(13,24)$. This study tries to compare the results with similar studies carried in Ethiopia, but due to lack of adequate local information comparison were not made sufficiently.

In conclusion, diarrhoea is one of the clinical manifestation in HIV patients particularly those with AIDS. This might be caused by various etiological agents. Among those ethiological agents coccidian parasites like Isospora belli and Cryptosporidum are the causative agent of life threatening chronic watery diarrhoea, weight loss and malabsorption. This will make the persons sense of well being and the ability to carry out daily activities profoundly impaired. In this study these two opportunistic parasites were highly prevalent among HIV/AIDS groups. Besides those opportunistic parasites the non opportunistic parasite Strongyloides stercoraris and the newly emerging diarrhoeagenic parasite Blastocystis were also prevalent in HIV/AIDS groups. But the overall distribution is not significantly different in each group.

Therefore diagnosis and treatment of those non opportunistic parasites and other public health measures are important to reduce the burden of this infection in HIV positive and HIV negative groups, since intestinal parasites represents a well known health problems of developing countries. 


\section{References}

1. Joint United Nation Program on HIV-1/AIDS. UNAIDS/WHO. AIDS epidemic update. 2004. World Health Organization, Geneva, 2005

2. WHO Expert Committee. Prevention and control of Schistosomiasis and soil transmitted helminthiasis. World Health Organization Technical Report Series 2002; 912: 1-57

3. Erko B, Medhin G. Human helminthiasis in Wendo Genet, southern Ethiopia with emphasis on geohelminthiasis. Ethiopian Medical Journal 2003; 41: 333with

4. Getahun $T$. The prevalence of intestinal helminthic infections and associated risk factors among school children in Babile town, Eastern Ethiopia. Ethiopian Journal of Health Development 2005; 19(2): 140-147

5. Jemaneh $L$. Comparative prevalence of some common intestinal helminths infections in different altitudinal regions in Ethiopia. Ethiopian Medical Journal 1998; 36:1-8

6. Legesse M, Erko B. Prevalence of intestinal parasites among school children in a rural area close to south east of Lake Langano, Ethiopia. Ethiopian Journal of Health Development 2004; 18: 116-12

7. Julia Maria, Costa- Cruz. Intestinal parasites in AIDS and HIV positive patients in Uberlândia, Minas Gerais. Bruzil, Mem. Inst oswaldo cruz. Rio de Jeneiro. Nov/Dec 1996;9(16): 685-686

8. Wiwanit Kit V. Intestinal parasitic infections in Thai HIV- infected patients at different immunity status. April 2000

9. Sorvillo F. Epidemiology of Isosporiosis among persons with acquired immunodeficiency syndrome in Los angles country. American Journal of immunodeficiency syndrome in Los angles country.
Tropical Medicine and Hygiene. 1995; 53(6): 656-659

10. Cotte-H. prevalence of intestinal protozoans in French patients with HIV. Journal of Acquired Immunodeficiency Syndrome. 1993 Sep; 6(9):1024-1029

11. Escobedo-A.A. Prevalence of intestinal parasites in Cuban acquired immunodeficiency syndrome(AIDS) patients. Acta Tropica. 1999Jan; 72(1):125-130

12. Ayyagati A. Spectrum of opportunistic infection in human immunodeficiency virus (HIV) infected cases in a tertiary care hospital. Indian Journal of Medical Microbiology. 1999; 17(2): 78-80
13. Morales G. Opportunistic and non opportunistic parasites in HIV-positive and negative patients with diarrhoea in Tanzania, Tropical Medicine and Parasitology. 1995, Jun; 46(2) 109-114

14. Therizol- Ferly M, et al. Chronic diarrhoea and parasitosis in adult patients suspected to have AIDS in Ivory Coast. Bull. De LA Soc. DE Path. Exo. ET DE Sel. Filiales. 1989; 92(2):690-693

15. Henry Mc. Parasitological observation of chronic diarrhoea in suspected AIDS adults patients in Kinshasa (Zaire). Transaction of Royal Society of Tropical Medicine and Hygiene, 1986; 80(2): 309-310

16. Mekonnen Y, Geskus RB, Hendriks JC, Messele T, Borghans J, Miedema F, Wolday D, Coutinho RA, Dukers NH. Low CD4 T cell counts before HIV-1 seroconversion do not affect disease progression in Ethiopian factory seroconversion do not affect disease progression in Ethiopian
workers. J Infect Dis. 2005 Sep 1;192(5):739-48. Epub 2005 Jul 22.

17. Fisseha B. Diarrhoea- associated parasitic infectious agent in AIDS patients with selected Addis Ababa Hospitals, Ethiopian Journal of Health Development 1999; 13(3): 169-173

18. W/Michael T, Tsegaye A, Tobias de Wit,Worku M.,Masho W.,Arnaud Fontanet. Increased incidence of intestinal parasitic infections in HIV positive when compared to HIV negative individuals: results from a two years prospective study. ETH. Med. J. 1999; 37 sep: 124.

19. Ethiopian Health and Nutrition Institute. Manual for HIV-1 Diagnosis. 2002 Addis Ababa, Ethiopia

20. Cheesbrough M. District laboratory practice in Tropical countries, Tropical health technology, UK, 1998 Part I: 192-198

21. D. Smith Philip. Gastro intestinal infections in AIDS. Annals of Internal Medicine, Jan 1992;116(1): 63-76

22. Abillo Tadesse, Afework Kassu. Intestinal parasite isolates in AIDS patients with chronic diarrhoea in Gondar Teaching Hospital, North west Ethiopia. Ethiop Med J. 2005; 43(2):93-6.

23. Endeshaw T, Mohammed H, Woldemichael T. Cryptosporidium parvum and other instestinal parasites among diarrhoeal patients referred to EHNRI in Ethiopia. Ethiop Med J. 2004 Jul; 42(3):195-8.

24. Hailemariam G, Kassu A, Abebe G, Abate E, Damte D, Mekonnen E, Ota F. Intestinal parasitic infections in HIV/AIDS and HIV seronegative individuals in a teaching hospital, Ethiopia. Jpn J Infect Dis. 2004 Apr; 57(2):41-3. 